\title{
Differences in nutrient and energy contents of commonly consumed dishes prepared in restaurants $v$. at home in Hunan Province, China
}

\author{
Xiaofang Jia ${ }^{1} \uparrow$, Jiawu Liu ${ }^{2} \dagger$, Bo Chen ${ }^{3}$, Donghui Jin ${ }^{2}$, Zhongxi Fu ${ }^{2}$, Huilin Liu ${ }^{2}$, Shufa Du ${ }^{4}$, \\ Barry M Popkin ${ }^{4}$ and Michelle A Mendez ${ }^{4, *}$ \\ 'National Institute for Nutrition and Health, Chinese Center for Disease Control and Prevention, Beijing, People's \\ Republic of China: ${ }^{2}$ Department of Non-communicable Disease Prevention, Hunan Center for Disease Control and \\ Prevention, Changsha, Hunan Province, People's Republic of China: ${ }^{3}$ Center for Chemical Analysis, College of \\ Chemistry and Chemical Engineering, Hunan Normal University, Changsha, Hunan Province, People's Republic of \\ China: ${ }^{4}$ Department of Nutrition, Gillings School of Global Public Health, Carolina Population Center, University of \\ North Carolina at Chapel Hill, Chapel Hill, NC 27516-2524, USA
}

Submitted 12 April 2017: Final revision received 3 November 2017: Accepted 17 November 2017: First published online 8 January 2018

\begin{abstract}
Objective: Eating away from home is associated with poor diet quality, in part due to less healthy food choices and larger portions. However, few studies account for the potential additional contribution of differences in food composition between restaurant- and home-prepared dishes. The present study aimed to investigate differences in nutrients of dishes prepared in restaurants $v$. at home.

Design: Eight commonly consumed dishes were collected in twenty of each of the following types of locations: small and large restaurants, and urban and rural households. In addition, two fast-food items were collected from ten KFC, McDonald's and food stalls. Five samples per dish were randomly pooled from every location. Nutrients were analysed and energy was calculated in composite samples. Differences in nutrients of dishes by preparation location were determined.

Setting: Hunan Province, China.

Subjects: Na, K, protein, total fat, fatty acids, carbohydrate and energy in dishes. Results: On average, both the absolute and relative fat contents, SFA and Na:K ratio were higher in dishes prepared in restaurants than households $(P<0.05)$. Protein was $15 \%$ higher in animal food-based dishes prepared in households than restaurants $(P<0 \cdot 05)$. Quantile regression models found that, at the 90th quantile, restaurant preparation was consistently negatively associated with protein and positively associated with the percentage of energy from fat in all dishes. Moreover, restaurant preparation also positively influenced the SFA content in dishes, except at the highest quantiles.

Conclusions: These findings suggest that compared with home preparation, dishes prepared in restaurants in China may differ in concentrations of total fat, SFA, protein and $\mathrm{Na}: \mathrm{K}$ ratio, which may further contribute, beyond food choices, to less healthy nutrient intakes linked to eating away from home.
\end{abstract}

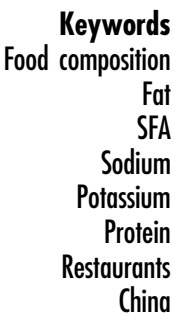

Changes in the food environment resulting from urbanization and globalization have led to a rise in food consumption away from home, not only in Western industrialized countries such as the USA, but also in rapidly industrialized countries including China ${ }^{(1-3)}$. Between 2000 and 2008, the share of expenditures on

$\dagger$ These authors contributed equally as first authors. food consumed at home in China's urban population declined from 85.3 to $79.4 \%$, while that spent on food eaten away from home increased from 14.7 to $20 \cdot 6 \%$, of which restaurant food comprised the majority ${ }^{(4)}$.

These shifts towards eating away from home have raised concerns that restaurant meals may negatively influence diet quality. Numerous studies report that eating away from home is associated with adverse patterns of 
nutrient intake due to a tendency to select less healthy foods in restaurants, and to consume larger portions, compared with home consumption ${ }^{(5,6)}$. For example, a systematic review of twenty-nine eligible studies reported that eating away from home was associated with a higher total energy intake and a greater energy contribution from fat in the daily diet ${ }^{(6)}$. Burke et $a l .{ }^{(7)}$ and Burns et $a l^{(8)}$ reported that eating away from home is associated with lower intakes of beneficial micronutrients, particularly vitamin $\mathrm{C}$, $\mathrm{Ca}$ and $\mathrm{Fe}$. Restaurant meals tend to contain higher levels of nutrients of concern, including energy, fat, saturated fat and $\mathrm{Na}$, which have been shown to increase the risk of obesity, diabetes, hypertension and heart disease $^{(9)}$. It has been reported that restaurant meals are higher in $\mathrm{Na}^{(10,11)}$ and fat ${ }^{(12)}$ compared with dishes prepared at home.

Recently, studies highlighting the poor nutrient profiles of commercially packaged foods and fast-food restaurant dishes $^{(13,14)}$ - notably high energy density and Na content - have raised the concern that eating away from home may also negatively affect diet quality in part due to the inferior nutrient composition of similar foods prepared in restaurants $v$. at home. Such disparities may arise in part because of differences in preparation methods, ingredients and recipes. For example, restaurant dishes may differ in added sugars, salt, Na-containing sauces or condiments, amounts and types of cooking fats used, and reliance on key ingredients that may be pre-processed ${ }^{(15)}$. To date, however, studies evaluating differences in the nutrient composition of similar foods prepared in restaurants $v$. households are extremely scarce.

To fill this gap in the literature, we conducted an exploratory study in Hunan Province, China, in which we compared the nutrient composition of eight commonly consumed dishes prepared in restaurants $v$. at home by chemically determining the nutrient contents of these dishes. In addition, we analysed the composition of two dishes frequently ordered from fast-food restaurants and food stalls. Analyses in the present study focused on total fat and SFA, protein, energy density, $\mathrm{Na}$ and the Na:K ratio, all dietary factors highly associated with cardiometabolic functioning and chronic disease risk ${ }^{(9)}$. Along with differences in mean contents, we examined variability in nutrient contents and evaluated disparities in nutrient contents at extremes in the distribution, where higher intakes of these non-beneficial dietary factors may be especially relevant for health ${ }^{(16)}$.

\section{Materials and methods}

\section{Study samples}

We randomly selected twenty of each of the following types of preparation locations in Changsha, Hunan Province, China: (i) small restaurants, defined as dining areas smaller than $30 \mathrm{~m}^{2}\left(\sim 323 \mathrm{ft}^{2}\right)$ in size, without private dining rooms, and offering a vegetable dish cheaper than 20 Yuan ( \$US 4); (ii) large restaurants, defined as dining areas $30-100 \mathrm{~m}^{2}$ (323-1076 $\left.\mathrm{ft}^{2}\right)$ in size, with private dining rooms, and offering vegetable dishes costing 20-30 Yuan (\$US 4-6); (iii) households in urban areas of Changsha, the provincial capital city; and (iv) households in rural areas near that city. We also randomly selected ten Kentucky Fried Chicken (KFC) outlets, ten McDonald's outlets and ten food stalls in the city. We purchased eight dishes, identified as the most commonly consumed dishes in this area based on data from the China Health and Nutrition Survey ${ }^{(17)}$, from each of the forty fullservice restaurants and asked each of the forty households to make the same eight dishes using their usual cooking practices. These dishes included five animal food-based dishes (sliced pork with dried bean curd; shredded pork with green pepper; stir-fried beef with garlic scape; stir-fried shredded chicken breast with red chili pepper; stir-fried tomato and scrambled eggs), two vegetable- or legume-based dishes (pan-fried tofu; stir-fried sponge gourd) and one grain-based dish (fried rice with eggs). We purchased Youtiao (Chinesestyle fried dough) from each of the ten KFC and ten food stalls, and chicken burgers from each of the ten KFC and ten McDonald's (McDonald's do not sell Youtiao). We collected all dishes in previously acid-washed and heat-dried ceramic plates, and fast-food items (fried dough and chicken burgers) in paper bags.

\section{Sample preparation}

Each collection day, we randomly chose five sampling sites from the twenty preparation locations of each type (small restaurants, large restaurants, urban households and rural households) and five from the ten KFC, McDonald's and food stalls. We collected the eight commonly consumed dishes or two fast-food items from each location and immediately transferred them to the central laboratory. We photographed, coded and weighed all samples, and subtracted the weight of plates and paper bags when we calculated the weight of food samples. We then pooled the five samples of the same dish from the same type of location and mixed them thoroughly in an acid-washed and heat-dried glass container. We drew $300 \mathrm{~g}$ of the mixed samples and homogenized them at room temperature. After homogenization, we split the sample into four $50 \mathrm{ml}$ tubes, two of which were immediately transferred on dry ice to the collaborating accredited laboratory for analysis. The other two homogenized samples were stored at $-80^{\circ} \mathrm{C}$. The remaining samples were discarded. A total of four composite samples of each dish from each type of preparation location were produced, except in the case of fried dough, for which we analysed two composite samples from fast-food restaurants or food stalls.

\section{Measurement of nutrient concentrations}

We conducted a variety of chemical analyses on each composite sample. A total of thirty-one fatty acids and two unseparated fatty acids were determined with hydrolytic 
extraction followed by GC (model GC-2010 gas chromatograph; Shimadzu, Japan) according to the Chinese National Standards of GB/T 22223-2008 ${ }^{(18)}$. SFA, MUFA and PUFA were calculated by summing the content of corresponding fatty acids. In detail, SFA included butyric, hexanoic, octanoic, decanoic, undecanoic, dodecanoic, tridecylic, tetradecanoic, pentadecanoic, hexadecanoic, heptadecanoic, octadecanoic, eicosanoic, docosanoic, tricosanoic and tetracosanoic acids; MUFA contained 9-tetradecenoic, cis-10-pentadecenoic, 9-hexadecenoic, cis-10-heptadecenoic, cis,trans-oleic, cis-11-eicosenoic and cis-13-docosenoic acids; and PUFA involved cis,translinoleic, $\gamma$-linolenic, $\alpha$-linolenic, cis-11,14-eicosadienoic, cis-11,14,17-eicosatrienoic, arachidonic, cis-5,8,11,14,17eicosapentaenoic and $c i s-13,16$-docosadienoic acids. Since it has been recommended to replace SFA with unsaturated fatty acids (UFA) in the diet to lower CVD risk ${ }^{(19)}$, we also estimated UFA as the sum of MUFA, PUFA and the unseparated methyl docosahexaenoate and tetracosenoic acids. Total fat content was defined as the sum of SFA, UFA and the unseparated cis-8,11,14-eicosatrienoic acid methyl ester and heneicosanoic acid. Total N content was determined with the Kjeldahl method (model KDM-A digital thermostat heater; Huawei, China) based on the national standardized method (GB 5009.5-2010) ${ }^{(20)}$, then multiplied by a conversion factor of 6.25 to convert into protein content ${ }^{(21)}$. Total carbohydrates were determined with a spectrophotometric method (model UV-1780 spectrophotometer; Shimadzu), according to the established standard of GB/T 9695.31-2008 ${ }^{(22)}$. Energy content (kcal/100 g) was defined as the sum of values of all energy-producing nutrients, including protein, fat and carbohydrate, multiplied by their energy conversion factor $(4 \mathrm{kcal} / \mathrm{g}(17 \mathrm{~kJ} / \mathrm{g})$ for protein or carbohydrate; $9 \mathrm{kcal} / \mathrm{g}$ $(37 \mathrm{~kJ} / \mathrm{g})$ for fat $)^{(23)}$. The percentages of energy from protein, fat and carbohydrate were calculated. Flame atomic emission spectrometry was used for $\mathrm{Na}$ and $\mathrm{K}$ content (model AA-6880 atomic absorption spectrophotometer; Shimadzu) according to the standard methods of GB/T 5009.91-2003 released by the Standardization Administration of China ${ }^{(24)}$, and Na:K ratios were calculated. All analyses of the composite samples were carried out in duplicate and externally validated using certified reference materials. Chemical analysis output was given in grams per $100 \mathrm{~g}$ of food analysed for protein, fat and carbohydrate, in milligrams per gram of food analysed for $\mathrm{Na}$ and $\mathrm{K}$, and in micrograms per gram of food analysed for various fatty acids.

\section{Data analysis}

We classified the eight dishes into three types: animal food-based (five dishes); vegetable/legume-based (two dishes); and grain-based (one dish). Nutrient and energy contents of each of the three types of dish were expressed as the mean and standard deviation and as percentiles (10th, 25th, 50th, 75th and 90th). Primary analyses were performed by comparing all restaurants with all households; supplementary analyses were done among various locations by stratifying restaurants into small and large types, and households into urban and rural types. Concentrations of nutrients and energy for all dishes combined were also described and differences in content by preparation location were analysed. Differences in the mean nutrient and energy contents of dishes provided by restaurants and households were evaluated by ANOVA. If the data were not normally distributed or the variance was heterogeneous, a logarithmic or square-root transformation was performed before analysis. Kruskal-Wallis tests were used whenever parametric test assumptions could not be satisfied. We used quantile regression models to estimate the significance of differences in nutrient and energy contents at higher $v$. lower percentiles of the distribution by dish preparation location. In addition, using the above-mentioned methods, we described the nutrient contents of the two fast foods, and evaluated how the contents of chicken burgers differed from other meatbased dishes (animal food-based dishes excluding stirfried tomato and scrambled eggs) prepared in restaurants or households. $P$ values less than 0.05 were considered statistically significant. All analyses were performed using the statistical software package SAS version 9.3.

\section{Results}

\section{Macronutrient and energy contents, restaurant $\mathbf{v}$. bousebold dishes}

Tables 1 and 2 present differences by preparation location in the nutrient and energy contents of each type of commonly consumed dish (animal food-based, vegetable/ legume-based and fried rice), as well as differences for all dishes combined. On average, restaurant-prepared dishes showed higher fat, both in absolute amount (3.66 v. $3.22 \mathrm{~g} /$ $100 \mathrm{~g} ; P=0.029)$ and as a percentage of energy (21.03 $v$. $16.04 \% ; P=0.001)$, as well as higher contents of SFA $(1.10 v \cdot 0.84 \mathrm{~g} / 100 \mathrm{~g} ; P=0.003)$ and PUFA $(1.13 v .0 .83 \mathrm{~g} /$ $100 \mathrm{~g} ; P=0.020)$ than household-prepared equivalents. There was a $15 \%$ greater protein content in householdmade dishes with animal foods compared with restaurantmade counterparts ( $45.51 v .39 .53 \mathrm{~g} / 100 \mathrm{~g} ; P=0.029)$, as well as a $9 \%$ higher energy content $(231.29 v .211 .51 \mathrm{kcal} /$ $100 \mathrm{~g}(967.72 v .884 .96 \mathrm{~kJ} / 100 \mathrm{~g}) ; P=0.043)$. Similar to all dishes combined, for vegetable/legume-based dishes, both absolute concentration of fat $(3.03 v$. $1.89 \mathrm{~g} / 100 \mathrm{~g}$; $P=0 \cdot 041)$ and the percentage of energy from fat $(30 \cdot 81 v$. $18.22 \% ; P=0.004)$, as well as absolute SFA content $(0.90$ v. $0.39 \mathrm{~g} / 100 \mathrm{~g} ; P<0.001)$, were higher in restaurantprepared versions.

We also found significant differences in protein, SFA, percentage of energy from fat and energy content in dishes combined among small restaurants, large restaurants, urban households and rural households $(P<0.05$ 
Table 1 Differences in nutrient content of dishes by preparation location, Hunan Province, China. The study was conducted in August 2013 and the chemical measurements were performed during August-October 2013

\begin{tabular}{|c|c|c|c|c|c|}
\hline & \multicolumn{2}{|c|}{ Restaurant } & \multicolumn{2}{|c|}{ Household } & \multirow[b]{2}{*}{$P$ value } \\
\hline & Mean & SD & Mean & SD & \\
\hline \multicolumn{6}{|l|}{ Animal food-based dishest } \\
\hline $\mathrm{Na}(\mathrm{mg} / \mathrm{g})$ & 5.98 & 1.68 & 5.92 & 1.71 & 0.868 \\
\hline $\mathrm{K}(\mathrm{mg} / \mathrm{g})$ & 4.71 & 1.45 & $5 \cdot 24$ & 1.54 & 0.119 \\
\hline $\mathrm{Na} \mathrm{K}$ & 1.33 & 0.35 & 1.18 & 0.31 & $0.049^{*}$ \\
\hline Protein (g/100 g) & 39.53 & $13 \cdot 21$ & $45 \cdot 51$ & $15 \cdot 25$ & $0.029 \|, *$ \\
\hline Fat $(\mathrm{g} / 100 \mathrm{~g})$ & $4 \cdot 17$ & 1.73 & 3.99 & 1.99 & 0.654 \\
\hline Carbohydrate $(\mathrm{g} / 100 \mathrm{~g})$ & 3.96 & 1.74 & 3.35 & 1.37 & 0.081 \\
\hline SFA $(g / 100 \mathrm{~g})$ & 1.24 & 0.61 & 1.07 & 0.69 & 0.116 \\
\hline UFA $(\mathrm{g} / 100 \mathrm{~g})$ & 2.92 & 1.53 & 2.91 & 1.46 & 0.970 \\
\hline MUFA (g/100 g) & 1.67 & 1.02 & 1.96 & 1.03 & $0.220 \|$ \\
\hline PUFA $(\mathrm{g} / 100 \mathrm{~g})$ & 1.25 & 0.77 & 0.94 & 0.55 & 0.079 \\
\hline \multicolumn{6}{|c|}{ Vegetable/legume-based dishes $\ddagger$} \\
\hline $\mathrm{Na}(\mathrm{mg} / \mathrm{g})$ & 5.89 & 1.25 & 5.33 & 0.97 & 0.163 \\
\hline $\mathrm{K}(\mathrm{mg} / \mathrm{g})$ & $2 \cdot 71$ & 0.83 & 2.73 & 0.59 & 0.948 \\
\hline $\mathrm{Na}: \mathrm{K}$ & $2 \cdot 23$ & 0.37 & 2.02 & 0.51 & 0.189 \\
\hline Protein $(\mathrm{g} / 100 \mathrm{~g})$ & 14.29 & $12 \cdot 19$ & $16 \cdot 90$ & 14.54 & $0.327 \|$ \\
\hline Fat $(g / 100 \mathrm{~g})$ & 3.03 & 1.65 & 1.89 & 1.36 & $0.041^{\star}$ \\
\hline Carbohydrate $(\mathrm{g} / 100 \mathrm{~g})$ & $3 \cdot 18$ & 1.09 & 3.25 & 1.32 & 0.870 \\
\hline SFA $(g / 100 \mathrm{~g})$ & 0.90 & 0.43 & 0.39 & 0.23 & $<0.001^{\star}$ \\
\hline UFA $(\mathrm{g} / 100 \mathrm{~g})$ & $2 \cdot 13$ & 1.31 & 1.50 & $1 \cdot 19$ & 0.165 \\
\hline MUFA $(\mathrm{g} / 100 \mathrm{~g})$ & 1.09 & 0.72 & 0.79 & 0.63 & 0.211 \\
\hline PUFA $(g / 100 \mathrm{~g})$ & 1.03 & 0.64 & 0.71 & 0.57 & 0.141 \\
\hline \multicolumn{6}{|l|}{ Fried rice with egg } \\
\hline $\mathrm{Na}(\mathrm{mg} / \mathrm{g})$ & 6.08 & 0.44 & 5.54 & 0.67 & 0.079 \\
\hline $\mathrm{K}(\mathrm{mg} / \mathrm{g})$ & 1.23 & 0.13 & 1.41 & 0.21 & 0.060 \\
\hline $\mathrm{Na}: \mathrm{K}$ & 4.98 & 0.48 & 3.99 & 0.66 & $0.004^{*}$ \\
\hline Protein $(\mathrm{g} / 100 \mathrm{~g})$ & $17 \cdot 22$ & 1.58 & 18.06 & 0.99 & 0.221 \\
\hline Fat $(\mathrm{g} / 100 \mathrm{~g})$ & 2.37 & 1.02 & 2.07 & 0.80 & $0 . \overline{514}$ \\
\hline Carbohydrate $(\mathrm{g} / 100 \mathrm{~g})$ & 32.44 & 1.38 & 33.44 & 3.51 & 0.466 \\
\hline SFA $(g / 100 \mathrm{~g})$ & 0.78 & 0.36 & 0.60 & 0.25 & 0.282 \\
\hline UFA ( $\mathrm{g} / 100 \mathrm{~g})$ & 1.60 & 0.68 & 1.46 & 0.59 & 0.675 \\
\hline MUFA $(\mathrm{g} / 100 \mathrm{~g})$ & 0.89 & 0.44 & 0.92 & 0.41 & 0.876 \\
\hline PUFA $(\mathrm{g} / 100 \mathrm{~g})$ & 0.71 & 0.29 & 0.54 & 0.26 & 0.236 \\
\hline \multicolumn{6}{|l|}{ Total dishes } \\
\hline $\mathrm{Na}(\mathrm{mg} / \mathrm{g})$ & 5.97 & 1.46 & 5.72 & 1.46 & $0.208 \S$ \\
\hline $\mathrm{K}(\mathrm{mg} / \mathrm{g})$ & 3.78 & 1.77 & 4.13 & 1.94 & $0.002^{*}$ \\
\hline $\mathrm{Na}: \mathrm{K}$ & 2.01 & 1.25 & 1.74 & 1.02 & $0.006 \|, *$ \\
\hline Protein $(\mathrm{g} / 100 \mathrm{~g})$ & 30.43 & $16 \cdot 87$ & 34.93 & $19 \cdot 60$ & 0.142 \\
\hline Fat $(g / 100 \mathrm{~g})$ & 3.66 & 1.76 & 3.22 & 1.99 & $0.029 \S,{ }^{*}$ \\
\hline Carbohydrate $(\mathrm{g} / 100 \mathrm{~g})$ & 7.33 & 9.69 & 7.09 & $10 \cdot 18$ & $0.674 \|$ \\
\hline SFA $(g / 100 \mathrm{~g})$ & 1.10 & 0.57 & 0.84 & 0.64 & 0.003 \\
\hline UFA $(\mathrm{g} / 100 \mathrm{~g})$ & 2.56 & 1.47 & 2.38 & 1.47 & $0.382 \|$ \\
\hline MUFA $(\mathrm{g} / 100 \mathrm{~g})$ & 1.43 & 0.94 & 1.54 & 1.04 & 0.755 \\
\hline PUFA ( $\mathrm{g} / 100 \mathrm{~g})$ & 1.13 & 0.71 & 0.83 & 0.55 & 0.020 \\
\hline
\end{tabular}

for all; see online supplementary material, Supplemental Tables 1 and 2). On average, for all dishes combined, both urban $(35.26 \mathrm{~g} / 100 \mathrm{~g})$ and rural $(34.59 \mathrm{~g} / 100 \mathrm{~g})$ households displayed significantly higher protein content than small $(30.77 \mathrm{~g} / 100 \mathrm{~g})$ and large $(30.08 \mathrm{~g} / 100 \mathrm{~g})$ restaurants, while dishes prepared in both small restaurants $(1 \cdot 11 \mathrm{~g} / 100 \mathrm{~g})$ and large restaurant $(1.09 \mathrm{~g} / 100 \mathrm{~g})$ had significantly higher SFA content compared with that from urban households $(0.72 \mathrm{~g} / 100 \mathrm{~g})$. Dishes from small restaurants $(21.42 \%)$ had a higher percentage of energy from fat than those prepared in urban $(15.29 \%)$ or rural $(16.80 \%)$ households; a higher percentage of energy from fat in large restaurants (20.63\%) was observed only relative to urban households. Dishes prepared in households displayed predominantly high protein content and a significantly higher estimated energy content when prepared in both urban $(198.24 \mathrm{kcal} /$ $100 \mathrm{~g}(829.44 \mathrm{~kJ} / 100 \mathrm{~g}))$ and rural $(195.84 \mathrm{kcal} / 100 \mathrm{~g}$ $(819.39 \mathrm{~kJ} / 100 \mathrm{~g})$ ) households $v$. in large restaurants $(182.32 \mathrm{kcal} / 100 \mathrm{~g}(762.83 \mathrm{~kJ} / 100 \mathrm{~g}))$; the higher energy content in dishes relative to small restaurants $(185.67 \mathrm{kcal} /$ $100 \mathrm{~g}(776.84 \mathrm{~kJ} / 100 \mathrm{~g}))$ was significant only for urban households. Concentrations of SFA in vegetable/legume- 
Table 2 Differences in energy content of dishes by preparation location, Hunan Province, China. The study was conducted in August 2013 and the chemical measurements were performed during August-October 2013

\begin{tabular}{|c|c|c|c|c|c|}
\hline & \multicolumn{2}{|c|}{ Restaurant } & \multicolumn{2}{|c|}{ Household } & \multirow[b]{2}{*}{$P$ value } \\
\hline & Mean & SD & Mean & SD & \\
\hline \multicolumn{6}{|l|}{ Animal food-based dishes $\dagger$} \\
\hline Energy $(\mathrm{kJ} / 100 \mathrm{~g})$ & 884.96 & 203.55 & $967 \cdot 72$ & $256 \cdot 44$ & $0.043 \|,{ }^{*}$ \\
\hline Energy (kcal/100 g) & 211.51 & $48 \cdot 65$ & $231 \cdot 29$ & 61.29 & $0.043 \|,{ }^{*}$ \\
\hline Energy from protein (\%) & $72 \cdot 72$ & 11.89 & 76.79 & $10 \cdot 65$ & $0.111 "$ \\
\hline Energy from fat (\%) & $19 \cdot 40$ & $10 \cdot 70$ & $16 \cdot 74$ & $9 \cdot 10$ & $0.210 \S$ \\
\hline Energy from carbohydrate (\%) & $7 \cdot 88$ & $3 \cdot 74$ & $6 \cdot 47$ & 3.80 & 0.099 \\
\hline \multicolumn{6}{|l|}{ Vegetable/legume-based dishes } \\
\hline Energy (kJ/100 g) & $406 \cdot 64$ & $230 \cdot 41$ & 408.57 & $266 \cdot 10$ & $0.651 \|$ \\
\hline Energy (kcal/100 g) & $97 \cdot 19$ & 55.07 & 97.65 & 63.60 & $0.651 \|$ \\
\hline Energy from protein (\%) & $48 \cdot 35$ & 23.96 & $55 \cdot 71$ & 24.68 & $0.399 "$ \\
\hline Energy from fat (\%) & $30 \cdot 81$ & $15 \cdot 40$ & $18 \cdot 22$ & $10 \cdot 28$ & $0.004 \S, *$ \\
\hline Energy from carbohydrate (\%) & $20 \cdot 84$ & $15 \cdot 60$ & $26 \cdot 07$ & 21.87 & 0.443 \\
\hline \multicolumn{6}{|l|}{ Fried rice with egg } \\
\hline Energy $(\mathrm{kJ} / 100 \mathrm{~g})$ & 920.52 & $50 \cdot 29$ & 939.68 & $62 \cdot 13$ & 0.508 \\
\hline Energy (kcal/100 g) & $220 \cdot 01$ & $12 \cdot 02$ & 224.59 & 14.85 & 0.508 \\
\hline Energy from protein (\%) & 31.28 & 1.77 & $32 \cdot 32$ & $3 \cdot 12$ & 0.427 \\
\hline Energy from fat (\%) & 9.62 & 3.83 & $8 \cdot 20$ & 3.05 & 0.428 \\
\hline Energy from carbohydrate (\%) & $59 \cdot 10$ & 3.48 & $59 \cdot 48$ & 3.74 & 0.838 \\
\hline \multicolumn{6}{|l|}{ Total dishes } \\
\hline Energy $(\mathrm{kJ} / 100 \mathrm{~g})$ & $769 \cdot 81$ & $288 \cdot 74$ & $824 \cdot 42$ & 341.54 & $0.401 \|$ \\
\hline Energy (kcal/100 g) & 183.99 & 69.01 & 197.04 & 81.63 & 0.401 \\
\hline Energy from protein (\%) & 61.45 & 21.55 & 65.96 & 21.48 & 0.248 \\
\hline Energy from fat (\%) & 21.03 & 13.09 & $16 \cdot 04$ & $9 \cdot 32$ & $0.001 \S, *$ \\
\hline Energy from carbohydrate (\%) & $17 \cdot 52$ & $18 \cdot 69$ & $18 \cdot 00$ & 21.07 & $0.674 \|$ \\
\hline
\end{tabular}

based dishes from various preparation locations were consistent with those in total dishes.

Supplemental Table 3 in the online supplementary material summarizes the percentiles for the distribution of nutrient and energy contents for each type of dish. Descriptive analyses indicated that percentiles (10th, 25th, 50th, 75th and 90th) of protein in total dishes prepared in households were somewhat higher compared with those in restaurant-prepared counterparts. Across the percentile distribution, differences between restaurants and households in the protein and energy contents of animal foodbased dishes were similar to those in total dishes. In contrast, the percentiles for the distribution of absolute and relative fat contents and those of SFA content distribution in total dishes, as well as for each dish subtype, were likely to be higher in restaurants relative to households.

We employed quantile regression models to examine the significance of the association between preparation location and nutrient composition overall. Figures 1-3 show estimates over the quantiles for each nutrient and energy along with the 95\% CI. At higher quantiles, dishes prepared in households had significantly higher protein (Fig. 1(a)), energy density (Fig. 2(a)) and energy percentage from protein (Fig. 2(b)), and significantly lower fat contribution to energy (Fig. 2(c)), compared with those prepared in restaurants, although this was not observed at lower quantiles. Moreover, estimates of the restaurant-household disparity generally increased at higher quantiles for the percentage of energy from fat (Fig. 2(c)). Restaurant preparation significantly and positively influenced concentrations of SFA distribution in total dishes at all but the highest quantiles (Fig. 3(a)). Restaurant preparation was also positively associated with PUFA content in dishes at lower percentiles (Fig. 3(d)). Table 3 presents tabulated results of the energy and nutrient contents of dishes for a selected set of quantiles (10th, 50th and 90th). Compared with households, restaurant preparation was associated with a decrease of $5.38(95 \%$ CI $-13 \cdot 18,-1.32) \mathrm{g} / 100 \mathrm{~g}$ and 27.77 (95\% CI -45.19, -9.59) kcal/100 g (116.19 (95\% CI -189.07, -40.12) $\mathrm{kJ} / 100 \mathrm{~g}$ ) in protein content and energy density, respectively, at the 90th quantile. However, restaurant-prepared dishes had a significantly higher fat contribution to total energy of 11.65 (95\% CI 3.99, 21.31\%) \% at the 90th quantile. Restaurant preparation was also associated with a greater SFA content of 0.18 (95\% CI 0.01, 0.39) and 0.44 $(95 \% \mathrm{CI} 0 \cdot 23,0 \cdot 67) \mathrm{g} / 100 \mathrm{~g}$ at the 10th and 50th quantiles, respectively, as well as with a higher PUFA content of $0 \cdot 20$ (95\% CI 0.02, 0.44) $\mathrm{g} / 100 \mathrm{~g}$ at the 50th quantile.

\section{Micronutrient contents, restaurant v. bousebold disbes}

On average, a lower concentration of $\mathrm{K}(3.78 v .4 .13 \mathrm{mg} / \mathrm{g}$; $P=0.002)$ and higher Na:K (2.01 v. 1.74; $P=0.006)$ were 


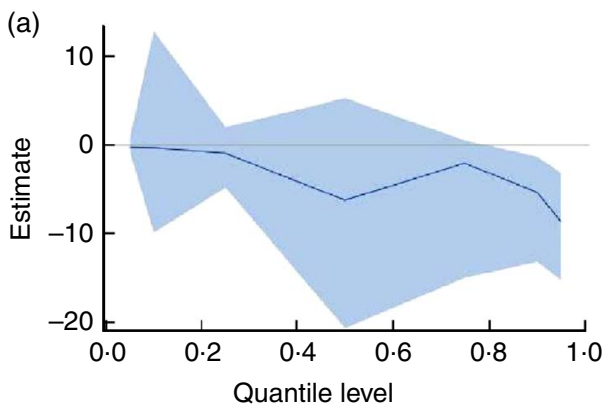

(b)

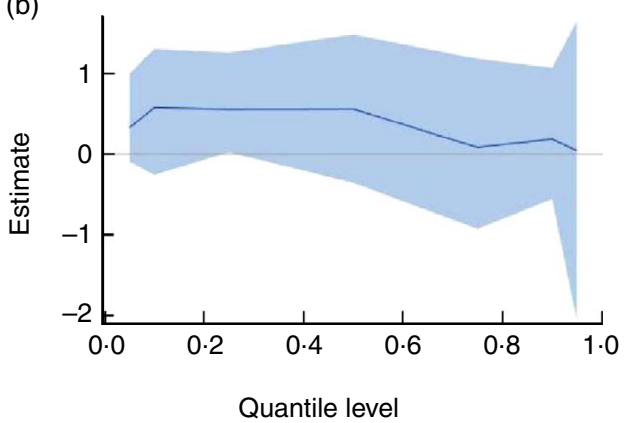

(c)

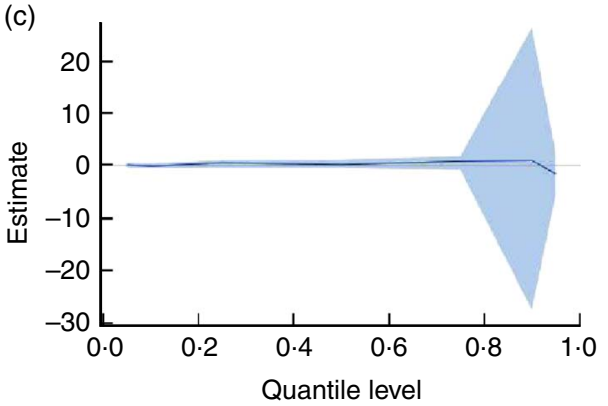

Fig. 1 (colour online) Effects of dish preparation location (restaurants $v$. households) on measured macronutrient content of dishes using quantile regression models, Hunan Province, China. Quantile regression estimates across quantiles of (a) protein, (b) fat and (c) carbohydrate are shown as the solid line. The shaded area around the estimates represents the $95 \% \mathrm{Cl}$ for the estimates. Compared with household, restaurant negatively and positively influenced protein and fat content of total dishes across the quantiles, respectively. And restaurant positively influenced carbohydrate content at higher quantiles. The study was conducted in August 2013 and the chemical measurements were performed during August-October 2013

found in restaurant-prepared total dishes relative to household-prepared counterparts as shown in Table 1. Dishes with animal foods prepared in restaurants showed higher $\mathrm{Na}$ : $\mathrm{K}$ than those from households $(P=0.049)$. Likewise, restaurant-made fried rice with egg displayed a significantly greater Na:K $(P=0.004)$ than household-prepared equivalents, although only marginal significance was observed for higher Na $(P=0.079)$ and lower $\mathrm{K}(P=0.060)$ individually.

Similar analyses were employed to investigate differences in nutrient contents by subtypes of dish preparation location (see online supplementary material, Supplemental Table 1). On average, $\mathrm{K}$ content in total dishes was significantly different among four types of preparation location $(P<0.001)$; the highest $\mathrm{K}$ was found in urban households $(4.31 \mathrm{mg} / \mathrm{g})$, while the lowest in large restaurants $(3.60 \mathrm{mg} / \mathrm{g})$. Additionally, significantly different Na:K ratio among various preparation locations was found in both dishes with animal foods $(P<0.026)$ and fried rice with egg $(P<0.031)$. Na:K ratio in large restaurantprepared dishes with animal foods (1.42) and fried rice (5.02) was higher than in urban household-prepared counterparts ( 1.10 and $3 \cdot 76$, respectively). Fried rice prepared in small restaurants also showed higher Na:K (4.94) relative to that prepared in urban households (3.76).

In general, the percentiles of $\mathrm{Na}$ in restaurant-prepared dishes, both for total dishes and dish types, tended to be high in comparison with household-prepared equivalents, although a negligible high $\mathrm{Na}$ content at more extreme percentiles (i.e. the 10th and 90th) was observed in some household-prepared dishes (see online supplementary material, Supplemental Table 3). Quantile regression models showed that in general coefficients for restaurant preparation increased with higher quantiles of $\mathrm{Na}$, except at the extremes (Fig. 4(a)). However, there was no significant association with preparation location at any of the selected quantiles (10th, 50 th and 90th) for $\mathrm{Na}, \mathrm{K}$ or their ratio (Table 3).

\section{Nutrient and energy contents of common fast-food disbes}

We also examined the nutrient and energy contents of two common fast foods (chicken burgers and fried dough) typically obtained only in fast-food restaurants and food stalls (see online supplementary material, Supplemental Table 4), and compared the macronutrient and energy contents of chicken burgers with those of total meat-based dishes prepared either in full-service restaurants or at home in the present study (Supplemental Table 5). The mean estimated energy content of chicken burgers $(283.89 \mathrm{kcal} /$ $100 \mathrm{~g}(1187 \cdot 80 \mathrm{~kJ} / 100 \mathrm{~g}))$ was significantly greater than that of other common meat-based dishes prepared in restaurants (231.71 kcal $/ 100 \mathrm{~g}(969.47 \mathrm{~kJ} / 100 \mathrm{~g}) ; P=0.001)$. In addition, the mean absolute $(36.17 \mathrm{~g} / 100 \mathrm{~g})$ and relative $(50.64 \%$ of energy) concentrations of protein in chicken burgers were lower than those in meat-based dishes from either restaurants $(45.07 \mathrm{~g} / 100 \mathrm{~g}$ and $77.54 \%$ of energy) or households $(52.06 \mathrm{~g} / 100 \mathrm{~g}$ and $80.73 \%$ of energy; $P<0.05$ for all). As expected given the high bread content, the opposite pattern was found for carbohydrate, with higher concentrations in chicken burgers than in other common meat-based dishes. No significant differences were observed for fat.

Regarding Chinese-style fried dough, the mean $\mathrm{Na}: \mathrm{K}$ ratio and the absolute and relative energy from carbohydrate appeared to be higher in samples from fast-food restaurants compared with those from food stalls (4.20 v. 2.66 for $\mathrm{Na}: \mathrm{K}$, $50.04 v .46 .65 \mathrm{~g} / 100 \mathrm{~g}$ for carbohydrate and 63.43 v. $59.30 \%$ for energy contribution from carbohydrate). We further compared the nutrient composition of Chinese fried dough with US doughnuts (National Nutrient Database, No. 18253), as there was no comparable food from restaurants or 
(a)

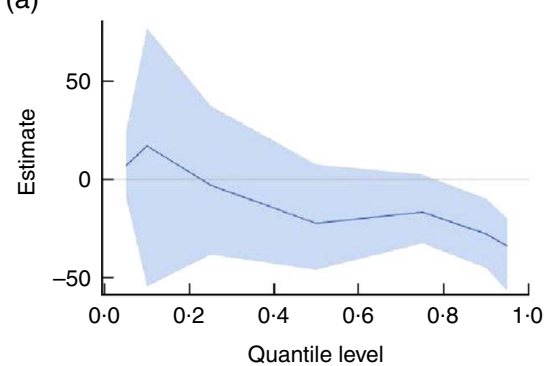

(c)

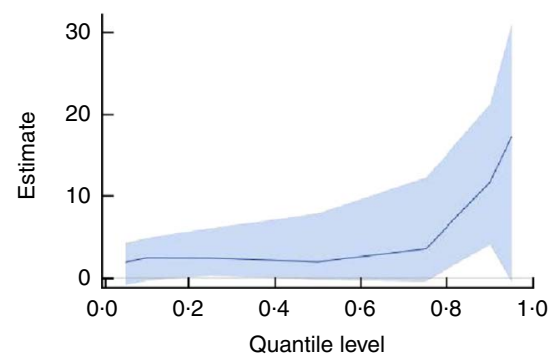

(b)

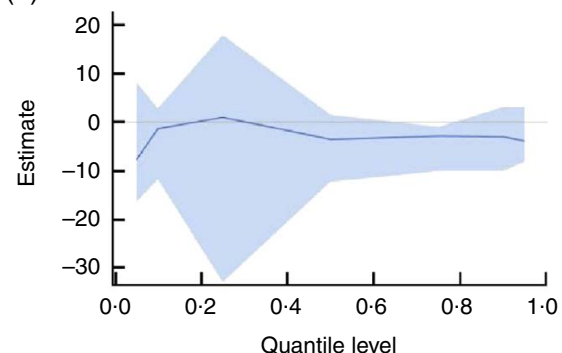

(d)

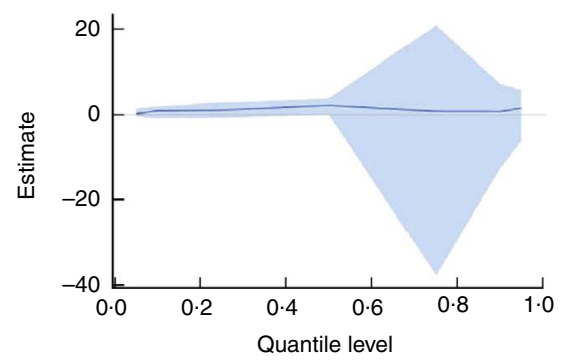

Fig. 2 (colour online) Effects of dish preparation location (restaurants $v$. households) on calculated energy content of dishes using quantile regression models, Hunan Province, China. Quantile regression estimates across quantiles of (a) energy, (b) percentage of energy from protein, (c) percentage of energy from fat and (d) percentage of energy from carbohydrate are shown as the solid line. The shaded area around the estimates represents the $95 \% \mathrm{Cl}$ for the estimates. Dishes prepared in households seemed to have higher energy and energy from protein than those prepared in restaurants at higher quantiles. The findings of contribution of fat to energy were opposite. The study was conducted in August 2013 and the chemical measurements were performed during AugustOctober 2013

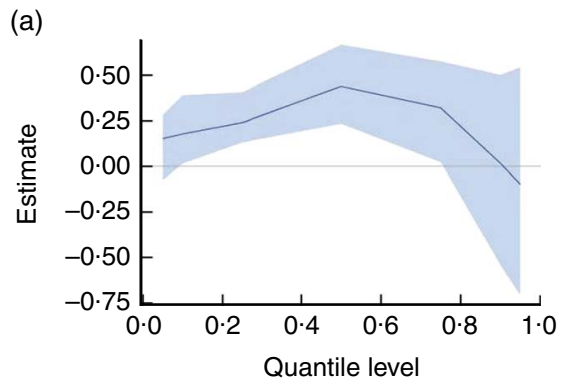

(c)

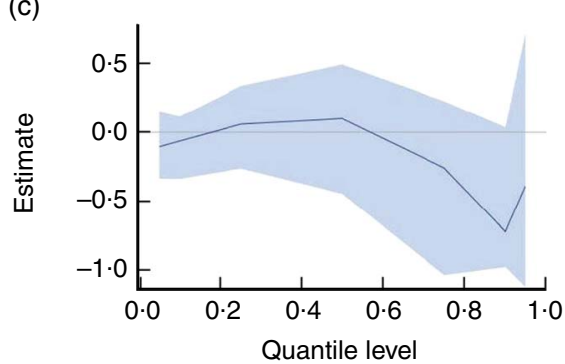

(b)

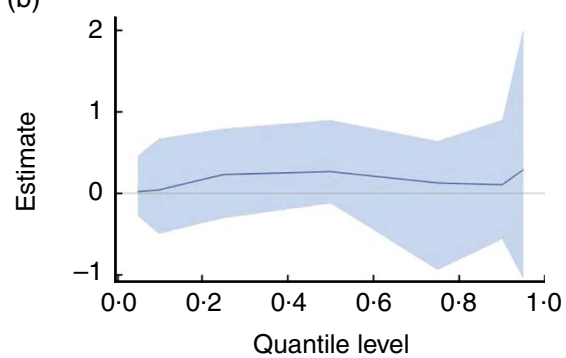

(d)

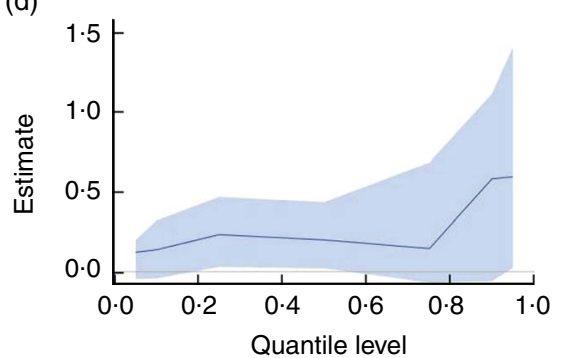

Fig. 3 (colour online) Effects of dish preparation location (restaurants $v$. households) on measured fatty acid content of dishes using quantile regression models, Hunan Province, China. Quantile regression estimates across quantiles of (a) SFA, (b) unsaturated fatty acids, (c) MUFA and (d) PUFA are shown as the solid line. The shaded area around the estimates represents the $95 \% \mathrm{Cl}$ for the estimates. Restaurant-prepared dishes were likely to contain higher SFA and unsaturated fatty acids, especially PUFA, compared with household-prepared dishes. The study was conducted in August 2013 and the chemical measurements were performed during August-October 2013

households in the present study. The mean $\mathrm{Na}$, $\mathrm{K}$ and protein content in our samples of fried dough were higher than levels reported in US doughnuts. Concentrations of these nutrients in fried dough $v$. in US doughnuts were $7.37 v .3 .45 \mathrm{mg} / \mathrm{g}$ for $\mathrm{Na}, 2.22 v \cdot 0.78 \mathrm{mg} / \mathrm{g}$ for $\mathrm{K}$ and $23.56 v \cdot 3 \cdot 10 \mathrm{~g} / 100 \mathrm{~g}$ for protein. 
Table 3 Effect of dish preparation location (restaurant $v$. household) on nutrient and energy contents: quantile regression estimates for selected quantiles of nutrient and energy distributions, Hunan Province, China. The study was conducted in August 2013 and the chemical measurements were performed during August-October 2013

\begin{tabular}{|c|c|c|c|c|c|c|}
\hline \multirow[b]{2}{*}{ Dependent variable } & \multicolumn{2}{|c|}{ 10th quantile } & \multicolumn{2}{|c|}{ 50th quantile } & \multicolumn{2}{|c|}{ 90th quantile } \\
\hline & Estimate† & $95 \% \mathrm{Cl}$ & Estimate† & $95 \% \mathrm{Cl}$ & Estimate† & $95 \% \mathrm{Cl}$ \\
\hline $\mathrm{Na}(\mathrm{mg} / \mathrm{g})$ & -0.31 & $-0.89,0.87$ & 0.35 & $-0 \cdot 11,1 \cdot 12$ & -0.07 & $-1.30,1.06$ \\
\hline $\mathrm{K}(\mathrm{mg} / \mathrm{q})$ & -0.36 & $-0.67,0.61$ & 0.10 & $-1.84,0.66$ & -0.49 & $-1.19,0.02$ \\
\hline $\mathrm{Na}: \mathrm{K}$ & 0.13 & $-0.07,0.36$ & 0.11 & $-0.06,0.44$ & 1.24 & $-1 \cdot 74,2 \cdot 19$ \\
\hline Protein $(\mathrm{g} / 100 \mathrm{~g})$ & -0.31 & $-9.92,12.85$ & $-6 \cdot 25$ & $-20 \cdot 70,5 \cdot 30$ & $-5 \cdot 38^{*}$ & $-13 \cdot 18,-1.32$ \\
\hline Fat $(\mathrm{g} / 100 \mathrm{~g})$ & 0.58 & $-0.26,1.31$ & 0.56 & $-0.36,1.49$ & 0.19 & $-0.56,1.07$ \\
\hline Carbohydrate $(\mathrm{g} / 100 \mathrm{~g})$ & -0.12 & $-0.45,0.40$ & 0.16 & $-0.42,1.14$ & 0.99 & $-27 \cdot 52,26 \cdot 60$ \\
\hline SFA $(\mathrm{g} / 100 \mathrm{~g})$ & $0 \cdot 18^{*}$ & $0.01,0.39$ & $0.44^{*}$ & $0.23,0.67$ & 0.02 & $-0.54,0.50$ \\
\hline UFA $(\mathrm{g} / 100 \mathrm{~g})$ & 0.04 & $-0.50,0.67$ & 0.27 & $-0.13,0.90$ & 0.11 & $-0.56,0.90$ \\
\hline MUFA ( $/ 100 \mathrm{~g})$ & -0.06 & $-0.34,0.11$ & 0.10 & $-0.45,0.49$ & -0.72 & $-0.98,0.04$ \\
\hline PUFA ( $\mathrm{g} / 100 \mathrm{~g})$ & 0.14 & $-0.04,0.32$ & $0.20^{*}$ & $0.02,0.44$ & 0.59 & $-0.06,1.12$ \\
\hline Energy (kJ/100 g) & 71.59 & $-228.53,323 \cdot 76$ & -93.35 & $-192 \cdot 72,32 \cdot 38$ & $-116 \cdot 19^{\star}$ & $-189 \cdot 07,-40 \cdot 12$ \\
\hline Energy (kcal/100 g) & $17 \cdot 11$ & $-54.62,77 \cdot 38$ & $-22 \cdot 31$ & $-46 \cdot 06,7.74$ & $-27.77^{*}$ & $-45 \cdot 19,-9.59$ \\
\hline Energy from protein (\%) & -1.41 & $-11 \cdot 83,2 \cdot 84$ & -3.59 & $-12.29,1.53$ & -3.05 & $-10.11,3.08$ \\
\hline Energy from fat $(\%)$ & 2.43 & $-0.35,4.89$ & 1.96 & $-0.26,7.88$ & $11.65^{\star}$ & $3.99,21.31$ \\
\hline Energy from carbohydrate (\%) & 0.93 & $-0.88,1.98$ & $2 \cdot 20$ & $-0.04,3.87$ & 0.75 & $-12.80,7.30$ \\
\hline
\end{tabular}

UFA, unsaturated fatty acids.

* Statistical significance of $P$ value is less than 0.05

†Quantile regression estimate of the influence of restaurant on nutrient and energy content of total dishes relative to household as a reference.

\section{Discussion}

With the exception of a few countries like the USA, which collect food composition data on branded foods, for most settings there is limited evidence on the extent to which commercial dishes, including those prepared in restaurants, may contain excessive concentrations of nutrients of concern such as $\mathrm{Na}$ and fat ${ }^{(25)}$. This is particularly true for lowand middle-income countries, where there are few data on the potential differences in nutrient composition of dishes prepared in restaurants $v$. at home, despite an increase in food eating away from home ${ }^{(26)}$. The present study collected and chemically analysed samples of eight frequently consumed dishes prepared in multiple restaurants $v$. in households in Hunan Province, China to compare concentrations of nutritional components of public health concern. Our key finding was that on average, compared with those from households, dishes prepared in restaurants had a higher $\mathrm{Na}: \mathrm{K}$ ratio, as well as higher absolute and relative contents of fat, most notably a greater SFA content, all nutrients identified as important dietary risk factors for chronic disease development ${ }^{(19,27,28)}$. Quantile regression models were employed to determine the extent to which differences in nutrient composition of dishes by preparation location varied not only at the mean, but also at the higher levels of the distribution where the influence on dietary intake may be especially potent. We found significantly lower levels of protein and energy, and a higher percentage of energy from fat, in restaurant- $v$. home-prepared dishes at the 90th quantile. A significant positive influence of restaurant preparation on SFA content was observed at the 10th and 50th quantiles. These findings from our study in China provide intriguing insights into the potential additional contribution - beyond the influence of food choices and portion sizes - of differences in nutrient composition to adverse nutritional impacts related to eating in restaurants as compared with the same dishes prepared in the home.

In supplementary analyses, we also found that dishes prepared in both small and large restaurants had a notably higher percentage of energy from fat than those prepared in urban and rural households (21.42 and 20.63 v. 15.29 and $16.80 \%$, respectively), and more pronounced SFA content than that in urban households (1.11 and 1.09 $v$. $0.72 \mathrm{~g} / 100 \mathrm{~g}$, respectively). Conversely, the protein content of dishes was considerably lower in small and large restaurants than in urban and rural households (30.77 and $30.08 v$ v 35.26 and $34.59 \mathrm{~g} / 100 \mathrm{~g}$, respectively). Dishes prepared in large restaurants also had the lowest $\mathrm{K}$ relative to other preparation locations. However, given our modest sample size and dish types, it is uncertain to what extent these findings may reflect variation in nutrient composition typical among dishes from these diverse types of restaurants and household settings.

There is considerable evidence that dietary $\mathrm{Na}$ and $\mathrm{K}$ intakes are associated with hypertension, which plays a key role in the development of $\mathrm{CVD}^{(29)}$. As a consequence, a growing body of research has focused not only on $\mathrm{Na}$ intake, but also on the $\mathrm{Na}$ content of foods prepared and consumed away from home, the frequency of which has risen steadily in recent decades ${ }^{(30-32)}$. Increasing attention to the potential health hazard posed by $\mathrm{Na}$ may motivate food reformulation and recipe adjustments by commercial establishments ${ }^{(33)}$. In our study, at most percentiles, the $\mathrm{Na}$ content was higher in dishes prepared in restaurants relative to those prepared in households. However, it is also important to note that at the highest quantiles, the $\mathrm{Na}$ content in home-prepared dishes in our sample from China was also high, indicating that $\mathrm{Na}$ content may also be problematic in dishes prepared in some households. 
(a)
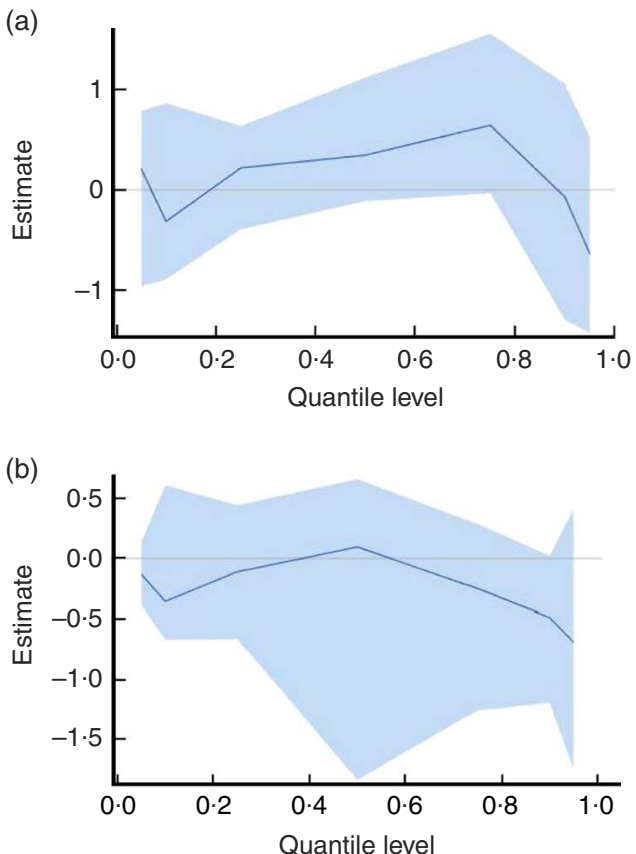

(c)

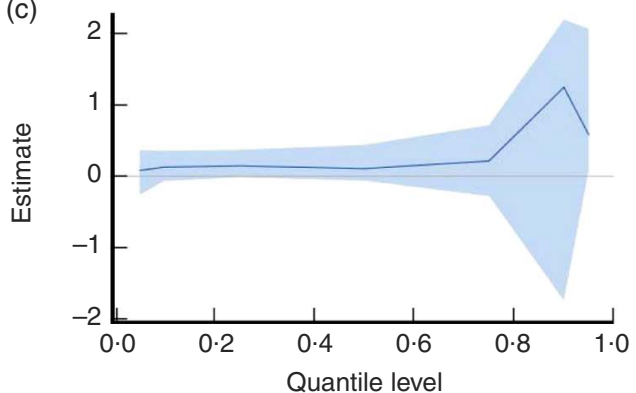

Fig. 4 (colour online) Effects of dish preparation location (restaurants $v$. households) on measured micronutrient content of dishes using quantile regression models, Hunan Province, China. Quantile regression estimates across quantiles of (a) sodium, (b) potassium and (c) ratio of sodium to potassium are shown as the solid line. The shaded area around the estimates represents the $95 \% \mathrm{Cl}$ for the estimates. Restaurant-prepared dishes tended to have higher sodium and ratio of sodium to potassium than household-prepared counterparts. The study was conducted in August 2013 and the chemical measurements were performed during AugustOctober 2013

Previous studies in a representative sample of Chinese adults estimated the mean $\mathrm{Na}$ intake to be $4700 \mathrm{mg} / \mathrm{d}^{(34)}$, far above the current WHO recommendation of $<2000 \mathrm{mg} / \mathrm{d}$ (5 g salt/d) ${ }^{(35)}$, the US dietary guideline of $<2300 \mathrm{mg} / \mathrm{d}^{(36)}$ and the Chinese recommendation of $<2400 \mathrm{mg} / \mathrm{d}(6 \mathrm{~g} \mathrm{salt} / \mathrm{d})^{(37)}$. Studies in China have shown that $43.7 \%$ of salt intake comes from household cooking and $43.4 \%$ from eating out, or a total of about $90 \%$ added during cooking (households plus cafeterias/restaurants $)^{(38,39)}$. Thus both household eating and dining out are major sources of $\mathrm{Na}$ consumption in China, where most $\mathrm{Na}$ is from discretionary sources; that is, from the use of added salt and Na-rich condiments such as soya sauces to dishes during cooking ${ }^{(38,40)}$.
In recent years, the prevalence of hypertension in China has increased to $25.2 \%$ in adults over the age of 18 years, as the country experienced rapid economic development, urbanization, population ageing and changes in traditional dietary habits and lifestyle ${ }^{(41)}$. A higher dietary $\mathrm{Na}: \mathrm{K}$ ratio is a significant risk factor not only for incidence of hypertension and CVD, but also for mortality from total and subtypes of stroke, CVD and all causes ${ }^{(29)}$. Our study found a greater mean $\mathrm{Na}: \mathrm{K}$ ratio in total dishes, especially animal food-based dishes and fried rice with egg, prepared in restaurants $v$. households, with the greatest difference of $24.8 \%$ found in egg fried rice. The higher $\mathrm{Na}: \mathrm{K}$ ratio in restaurant-prepared versions of common dishes may exacerbate the adverse impact of frequent restaurant consumption on health, and is of special concern in China. An international study comparing intake of $\mathrm{Na}, \mathrm{K}$ and their ratio using two $24 \mathrm{~h}$ urinary measures among Chinese, Japanese, UK and US populations found higher $\mathrm{Na}$, lower $\mathrm{K}$ and hence a higher $\mathrm{Na}: \mathrm{K}$ ratio in Asian diets, and especially the Chinese sample ${ }^{(42)}$.

Regarding macronutrients, data from the present study showed a higher fat content as well as a higher contribution of fat to energy, largely as a result of differences in vegetable/legume-based dishes, for foods prepared in restaurants compared with at home. In addition, there was a significantly higher protein content in dishes with animal foods prepared at home. Numerous studies in the USA and Europe have reported that restaurant consumption was associated with an increase in intake of total fat rather than protein or carbohydrates ${ }^{(30,43)}$. Although these studies did not take account of a potential difference in food composition between restaurant and household versions of the same dishes, they indicated restaurant consumption could be a risk factor for higher total fat intake, driven by differences in food choices and portions. Moreover, the finding of higher fat content in restaurant-prepared dishes, especially vegetable/legume-based dishes, was especially linked to higher levels of SFA than to UFA, which may imply potentially greater adverse health impact of eating out. It has been recommended to decrease SFA in the diet based on its influence on LDL cholesterol, a leading cause of atherosclerosis ${ }^{(19)}$. Dietary guidelines for both Chinese and American populations recommend consuming $<10 \%$ of energy from SFA for the general population and replacing SFA with $\mathrm{UFA}^{(36,37)}$. At present, SFA intake in China may be relatively low. The Chinese Nutrition and Health Survey 2002, based on dietary recall data, reported that the 75th percentile of the SFA contribution to energy in adults was $8.9 \%$, and that edible oils (contributing $44.7 \%$ to total SFA intake, in which $36.7 \%$ is from animal oil, a unique dietary habit for the Chinese population in previous years) and animal foods (43.2\%) were the top two sources of dietary SFA ${ }^{(44)}$. We found a significantly higher absolute concentration of SFA in restaurantprepared dishes than in household-prepared counterparts, as well as a higher percentage of energy from SFA 
(data not shown, $0.72 v \cdot 0.47 \%, P=0.002$ ). These findings suggest that even without changes in food choices, increased eating in restaurants might lead to increased intake of SFA. Taken together, the macronutrient composition of common restaurant foods may exacerbate non-beneficial patterns of nutrient intake in China. The higher fat content we observed in restaurant-prepared non-animal dishes may be due to factors such as the addition of more edible oils, while the greater amount of protein in dishes with animal foods prepared in households might reflect the use of higher quality (i.e. lean) and/ or larger amounts of meat relative to restaurant recipes. It was surprising that there was greater PUFA content in restaurant-prepared dishes, which may be attributed to differentiated availability of edible oils (67.2\%), plant foods $(20 \cdot 8 \%)$ and animal foods $(12 \cdot 0 \%)$, the top three sources of dietary PUFA in the general population in China ${ }^{(44)}$, between restaurants and households. Particularly, restaurants may use PUFA-rich edible oils, such as rapeseed, soyabean and salad oils, which are major contributors $^{(44)}$.

Many fast-food dishes are typically considered 'junk food' due to their poor nutrient content and high energy density $^{(45)}$. To further evaluate the potential influence of restaurant fast-food consumption on diet quality, we also measured and compared the composition of popular foods from this type of restaurant with more traditional counterpart foods (chicken burgers $v$. other meat-based dishes) or with comparable US foods (Chinese fried dough $v$. US doughnuts). In the present study, we found a greater energy density in chicken burgers from fast-food restaurants $(284 \mathrm{kcal} / 100 \mathrm{~g} \quad(1188 \mathrm{~kJ} / 100 \mathrm{~g}))$ relative to other common meat-based dishes $(232 \mathrm{kcal} / 100 \mathrm{~g}$ (971 kJ/100 g)) purchased from full-service restaurants, suggesting that frequent consumption of certain fast-food meals may potentially contribute to greater energy intake. In addition, compared with US doughnuts in the US Department of Agriculture's food composition database, the Chinese-style fried dough analysed in samples collected for the current study had a considerably higher $\mathrm{Na}$ content, as well as a lower $\mathrm{Na}: \mathrm{K}$ ratio, and a higher protein content. Together, these disparities in nutrient content suggest the possibility that, as reported in US studies ${ }^{(46)}$, frequent consumption of common fast-food restaurant dishes may be associated with less beneficial nutrient intakes. However, further study of larger samples is warranted given that large variability in the energy and nutrient contents of similar fast foods has been reported both between and within countries ${ }^{(47)}$. Although data are limited, food reformulation and shifts in products offered to improve nutritional profiles associated with eating in fast-food restaurants may be warranted to help improve diet quality worldwide.

A few limitations of the present study should be noted. After recruitment into the study, it is uncertain whether, and to what extent, households may have made potential changes in ingredients and recipes when preparing dishes compared with their usual methods. The study performed chemical determination of various nutrients in dishes. Unfortunately, fibre, an important contributor to energy which is also of interest due to its potential role in energy intake regulation, were not included. Although our data enabled us to analyse estimated total SFA concentrations, it is important to keep in mind that the health implications of specific SFA, such as those in coconut oils and dairy products, remain uncertain ${ }^{(48-50)}$. Additionally, we were only able to investigate a limited number of dishes and food preparation locations collected in one major metropolitan area, which limits our ability to generalize broadly from these findings.

\section{Conclusion}

In conclusion, the present study measured the nutrient content of common restaurant- and household-prepared equivalent dishes and found higher-quality dishes in the home. For example, the absolute and relative fat contents, $\mathrm{SFA}$ and $\mathrm{Na}: \mathrm{K}$ ratio were higher in dishes prepared in restaurants than households, while the protein content was higher in animal food-based dishes prepared in households $v$. in restaurants. These findings provide important insight into food composition differences between restaurant- and home-prepared dishes, which may contribute to different diet quality between restaurant and household eating beyond the influence of restaurant eating on food choices and portions. With the rapid industrialization of the Chinese food supply, we might expect congruence with excessive $\mathrm{Na}$ and fat (SFA) from eating away from home; however, there is no programme to systematically examine $\mathrm{Na}$ or other nutrient contents in restaurant foods in China. More research is needed to understand how the transformation of food consumption patterns will affect the nutritional status and health of the Chinese people.

\section{Acknowledgements}

Acknowledgments: The authors wish to thank Ms Frances L. Dancy for administrative assistance, and Ms Denise Ammons for graphics support, and for research assistance. Financial support: The authors are grateful for funding from the National Institutes of Health (NIH) to the Carolina Population Center at the University of North Carolina at Chapel Hill (grant number P2C HD050924) and for research grants from the NIH (grant numbers R01 HD30880, P30 DK056350, R01 HD38700); the NIH Fogarty International Center (grant number D43 TW009077); and Hunan Center for Disease Control and Prevention for financial support. The funding agencies had no role in the design, analysis or writing of this manuscript. Conflict of interest: None. Authorship: X.J. and J.L. contributed equally to this work. M.A.M., S.D., J.L. and B.M.P. designed the study; J.L., D.J., Z.F. and H.L. collected and processed all 
samples; B.C. was responsible for all the laboratory measurements; X.J., S.D. and M.A.M. analysed the data and wrote the manuscript. All authors significantly revised and approved the final manuscript. Ethics of human subject participation: Not applicable.

\section{Supplementary material}

To view supplementary material for this article, please visit https://doi.org/10.1017/S1368980017003779

\section{References}

1. Nielsen SJ, Siega-Riz AM \& Popkin BM (2002) Trends in food locations and sources among adolescents and young adults. Prev Med 35, 107-113.

2. Ma H, Huang J, Fuller F et al. (2006) Getting rich and eating out: consumption of food away from home in urban China. Can J Agric Econ 54, 101-119.

3. Zhai FY, Du SF, Wang ZH et al. (2014) Dynamics of the Chinese diet and the role of urbanicity, 1991-2011. Obes Rev 15, 16-26.

4. Dong X \& Hu B (2010) Regional difference in food consumption away from home of urban residents: a panel data analysis. Agric Agric Sci Procedia 1, 271-277.

5. Berkowitz S, Marquart L, Mykerezi E et al. (2016) Reducedportion entrées in a worksite and restaurant setting: impact on food consumption and waste. Public Health Nutr 19, 3048-3054.

6. Lachat C, Nago E, Verstraeten R et al. (2012) Eating out of home and its association with dietary intake: a systematic review of the evidence. Obes Rev 13, 329-346.

7. Burke SJ, McCarthy SN, O'Neill JL et al. (2007) An examination of the influence of eating location on the diets of Irish children. Public Health Nutr 10, 599-607.

8. Burns C, Jackson M, Gibbons C et al. (2002) Foods prepared outside the home: association with selected nutrients and BMI in adult Australians. Public Health Nutr 5, 441-448.

9. Setayeshgar S, Ekwaru JP, Maximova K et al. (2017) Dietary intake and prospective changes in cardiometabolic risk factors in children and youth. Appl Physiol Nutr Metab $\mathbf{4 2}$, $39-45$.

10. Lin BH \& Guthrie J (1996) The quality of children's diets at and away from home. Food Rev 19, 45-50.

11. Lin BH \& Frazao E (1997) Nutritional quality of foods at and away from home. Food Rev 20, 33-40.

12. Zoumas-Morse C, Rock CL, Sobo EJ et al. (2001) Children's patterns of macronutrient intake and associations with restaurant and home eating. J Am Diet Assoc 101, 923-925.

13. Gillespie C, Maalouf J, Yuan K et al. (2015) Sodium content in major brands of US packaged foods, 2009. Am J Clin Nutr 101, 344-353.

14. Paeratakul S, Ferdinand DP, Champagne CM et al. (2003) Fast-food consumption among US adults and children: dietary and nutrient intake profile. J Am Diet Assoc 103, $1332-1338$

15. Lee KW, Song WO \& Cho MS (2016) Dietary quality differs by consumption of meals prepared at home vs. outside in Korean adults. Nutr Res Pract 10, 294-304.

16. Prentice AM (2001) Overeating: the health risks. Obes Res $\mathbf{9}$, Suppl. 4, 234S-238S.

17. Popkin BM, Du S, Zhai F et al. (2010) Cohort profile: The China Health and Nutrition Survey - monitoring and understanding socio-economic and health change in China, 1989-2011. Int J Epidemiol 39, 1435-1440.

18. China Standard GB/T 22223-2008 (2008) Determination of Total Fat, Saturated Fat, and Unsaturated Fat in Foods -
Hydrolytic Extraction-Gas Chromatography. Beijing: Standards Press of China.

19. Sacks FM, Lichtenstein AH, Wu JHY et al. (2017) Dietary fats and cardiovascular disease: a presidential advisory from the American Heart Association. Circulation 136, e1-e23.

20. China Standard GB 5009.5-2010 (2010) Determination of Protein in Foods. Beijing: Standards Press of China.

21. Garza C, Scrimshaw NS \& Young VR (1978) Human protein requirements: interrelationships between energy intake and nitrogen balance in young men consuming the $1973 \mathrm{FAO} /$ WHO safe level of egg protein, with added non-essential amino acids. J Nutr 108, 90-96.

22. China Standard GB/T 9695.31-2008 (2008) Meat Products Determination of Total Sugars Content. Beijing: Standards Press of China.

23. Xu X, Byles JE, Shi Z et al. (2015) Evaluation of older Chinese people's macronutrient intake status: results from the China Health and Nutrition Survey. Br J Nutr 113, 159-171.

24. China Standard GB/T 5009.91-2003 (2003) Determination of Potassium and Sodium in Foods. Beijing: Standards Press of China.

25. Ng SW \& Dunford E (2013) Complexities and opportunities in monitoring and evaluating US and global changes by the food industry. Obes Rev 14, Suppl. 2, 29-41.

26. Wang Y, Wang L, Xue H et al. (2016) A review of the growth of the fast food industry in China and its potential impact on obesity. Int J Environ Res Public Health 13, E1112.

27. Whelton PK (2014) Sodium, potassium, blood pressure, and cardiovascular disease in humans. Curr Hypertens Rep 16, 465 .

28. Guasch-Ferre M, Babio N, Martinez-Gonzalez MA et al. (2015) Dietary fat intake and risk of cardiovascular disease and all-cause mortality in a population at high risk of cardiovascular disease. Am J Clin Nutr 102, 1563-1573.

29. Okayama A, Okuda N, Miura K et al. (2016) Dietary sodiumto-potassium ratio as a risk factor for stroke, cardiovascular disease and all-cause mortality in Japan: the NIPPON DATA80 cohort study. BMJ Open 6, e011632.

30. An R (2016) Fast-food and full-service restaurant consumption and daily energy and nutrient intakes in US adults. Eur J Clin Nutr 70, 97-103.

31. Rudelt A, French S \& Harnack L (2014) Fourteen-year trends in sodium content of menu offerings at eight leading fast-food restaurants in the USA. Public Health Nutr 17, 1682-1688.

32. Wu HW \& Sturm R (2014) Changes in the energy and sodium content of main entrees in US chain restaurants from 2010 to 2011. J Acad Nutr Diet 114, 209-219.

33. Ahuja JK, Wasswa-Kintu S, Haytowitz DB et al. (2015) Sodium content of popular commercially processed and restaurant foods in the United States. Prev Med Rep 2, 962-967.

34. Du S, Batis C, Wang $\mathrm{H}$ et al. (2014) Understanding the patterns and trends of sodium intake, potassium intake, and sodium to potassium ratio and their effect on hypertension in China. Am J Clin Nutr 99, 334-343.

35. World Health Organization (2012) Guideline: Sodium Intake for Adults and Children. Geneva: WHO.

36. US Department of Health and Human Services \& US Department of Agriculture (2015) 2015-2020 Dietary Guidelines for Americans, 8th ed. http://www.health. gov/dietaryguidelines/2015/resources/2015-2020_Dietary_ Guidelines.pdf (accessed June 2016).

37. Wang SS, Lay S, Yu HN et al. (2016) Dietary guidelines for Chinese residents (2016): comments and comparisons. J Zhejiang Univ Sci B 17, 649-656.

38. Zhang L, Zhao F, Zhang P et al. (2015) A pilot study to validate a standardized one-week salt estimation method evaluating salt intake and its sources for family members in China. Nutrients 7, 751-763. 
39. Zhao F, Zhang P, Zhang L et al. (2015) Consumption and sources of dietary salt in family members in Beijing. Nutrients 7, 2719-2730.

40. Anderson CA, Appel LJ, Okuda N et al. (2010) Dietary sources of sodium in China, Japan, the United Kingdom, and the United States, women and men aged 40 to 59 years: the INTERMAP study. I Am Diet Assoc 110, 736-745.

41. Hu L, Huang X, You C et al. (2017) Prevalence and risk factors of prehypertension and hypertension in Southern China. PLOS One 12, e0170238.

42. Zhou BF, Stamler J, Dennis B et al. (2003) Nutrient intakes of middle-aged men and women in China, Japan, United Kingdom, and United States in the late 1990s: the INTERMAP study. J Hum Hypertens 17, 623-630.

43. Orfanos P, Naska A, Trichopoulou A et al. (2009) Eating out of home: energy, macro- and micronutrient intakes in 10 European countries. The European prospective investigation into cancer and nutrition. Eur J Clin Nutr 63, Suppl. 4, S239-S262.

44. Zhang J, Meng L, Jiang Y et al. (2009) The dietary fatty acid intakes and their food sources among Chinese adults. Acta Nutrimenta Sinica 31, 424-427.
45. Bauer KW, Hearst MO, Earnest AA et al. (2012) Energy content of US fast-food restaurant offerings: 14-year trends. Am J Prev Med 43, 490-497.

46. Barnes TL, French SA, Mitchell NR et al. (2016) Fast-food consumption, diet quality and body weight: cross-sectional and prospective associations in a community sample of working adults. Public Health Nutr 19, 885-892.

47. Ziauddeen N, Fitt E, Edney L et al. (2015) Variability in the reported energy, total fat and saturated fat contents in fast-food products across ten countries. Public Health Nutr 18, 2962-2969.

48. DiNicolantonio JJ, Lucan SC \& O'Keefe JH (2016) The evidence for saturated fat and for sugar related to coronary heart disease. Prog Cardiovasc Dis 58, 464-472.

49. Liu AG, Ford NA, Hu FB et al. (2017) A healthy approach to dietary fats: understanding the science and taking action to reduce consumer confusion. Nutr J 16, 53.

50. Pimpin L, Wu JH, Haskelberg H et al. (2016) Is butter back? A systematic review and meta-analysis of butter consumption and risk of cardiovascular disease, diabetes and total mortality. PLoS One 11, e0158118. 